\title{
Uso de espécies nativas na restauração de ecossistemas florestais alterados pela retirada de seixo no nordeste paraense
}

\author{
Use of native species in the restoration of forest ecosystems altered by pebble removal in the \\ northeast of Pará
}

Uso de especies nativas en la restauración de ecosistemas forestales alterados por la remoción de guijarros en el noreste de Pará

Recebido: 08/06/2021 | Revisado: 13/06/2021 | Aceito: 19/07/2021 | Publicado: 26/07/2021

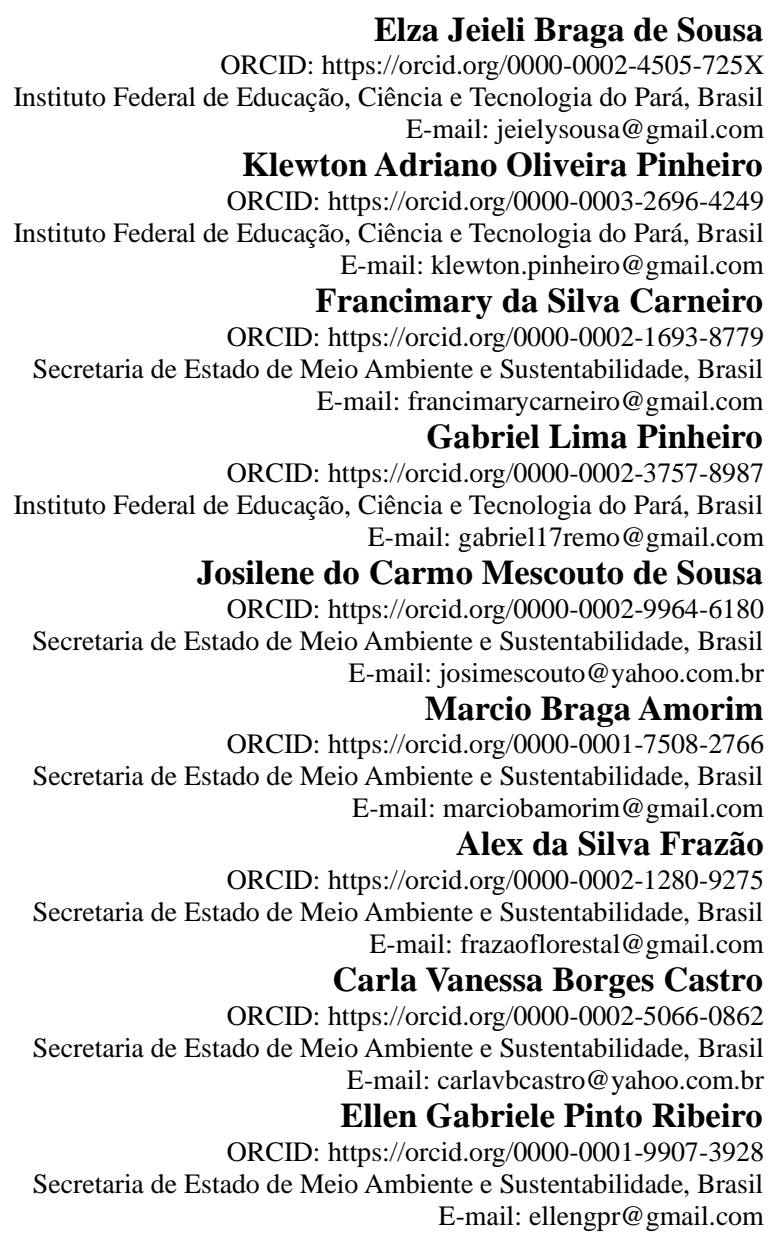

\section{Resumo}

As operações de lavra de seixo no município de Ourém tem início com o desmatamento, descampamento, escavação, carregamento, transporte e restauração das áreas mineradas. O objetivo deste trabalho é recomendar o uso de espécies florestais nativas pré-selecionadas com características ecológicas para favorecer a rápida recuperação de uma área ambiental degradada pela retirada de seixo. O procedimento de coleta de dados foi planejado em função dos objetivos geral e específicos da pesquisa, sendo realizadas coletas de dados em fontes secundárias e fontes primárias. Foi utilizada a estrada como trajeto para percorrer uma extensão de $3 \mathrm{~km}$ para realizar o diagnóstico florestal. A identificação florestal foi realizada através da observação dos indivíduos adultos nos dois lados da estrada. A lista de espécies adquirida na área da mineradora, podem ajudar na recuperação de áreas alteradas pelas atividades de mineração de seixo no município de Ourém - PA e de outras áreas com características semelhantes. A presença numerosa de famílias com tolerância a sol e de espécies pioneiras demonstra a diversidade florística desse ambiente e a qualidade do sítio. Foram registradas espécies típicas das florestas tropicais amazônicas como Bertholletia excelsa Humb. \& Bonpl, Aniba rosaeodora Ducke e Vouacapoua americana Aubl., demostrando que precisamos revegetar os ecossistemas degradados. 
Palavras-chave: Plantar; Recuperação; Áreas alteradas; Áreas degradadas; Mineração.

\begin{abstract}
Pebble mining operations in the municipality of Ourém begin with deforestation, clearing, excavation, loading, transport and restoration of mined areas. The objective of this work is to recommend the use of pre-selected native forest species with ecological characteristics to favor the rapid recovery of an environmental area degraded by the removal of pebbles. The data collection procedure was planned according to the general and specific objectives of the research, with data collection being carried out from secondary and primary sources. The road was used as a path to cover a length of $3 \mathrm{~km}$ to carry out the forestry diagnosis. Forest identification was carried out by observing adult individuals on both sides of the road. The list of species acquired in the mining company's area can help in the recovery of areas altered by pebble mining activities in the municipality of Ourém - PA and other areas with similar characteristics. The numerous presence of sun-tolerant families and pioneer species demonstrates the floristic diversity of this environment and the quality of the site. Typical species from Amazonian tropical forests such as Bertholletia excelsa Humb were recorded. \& Bonpl, Aniba rosaeodora Ducke and Vouacapoua americana Aubl., demonstrating that we need to revegetate degraded ecosystems.
\end{abstract}

Keywords: To plant; Recovery; Altered areas; Degraded areas; Mining.

\title{
Resumen
}

Las operaciones de extracción de guijarros en el municipio de Ourém comienzan con la deforestación, desmonte, excavación, carga, transporte y restauración de áreas minadas. El objetivo de este trabajo es recomendar el uso de especies forestales nativas preseleccionadas con características ecológicas para favorecer la rápida recuperación de un área ambiental degradada por la remoción de cantos rodados. El procedimiento de recogida de datos se planificó de acuerdo con los objetivos generales y específicos de la investigación, siendo la recogida de datos de fuentes primarias y secundarias. La carretera se utilizó como camino para cubrir una longitud de $3 \mathrm{~km}$ para realizar el diagnóstico forestal. La identificación del bosque se realizó mediante la observación de individuos adultos a ambos lados del camino. La lista de especies adquiridas en el área de la empresa minera puede ayudar en la recuperación de áreas alteradas por las actividades de extracción de cantos rodados en el municipio de Ourém - PA y otras áreas con características similares. La numerosa presencia de familias tolerantes al sol y especies pioneras demuestra la diversidad florística de este entorno y la calidad del sitio. Se registraron especies típicas de los bosques tropicales amazónicos como Bertholletia excelsa Humb. \& Bonpl, Aniba rosaeodora Ducke y Vouacapoua americana Aubl., Demostrando que necesitamos revegetar ecosistemas degradados.

Palabras clave: Plantar; Recuperación; Áreas alteradas; Zonas degradadas; Minería.

\section{Introdução}

Em 2020 o estado do Pará se destacou no cenário nacional como maior produtor de minérios do País. Tendo o primeiro lugar na produção de ferro, bauxita, cobre e caulim, além de ser grande produtor de manganês, níquel, calcário, ouro, gemas e outros minérios de uso na construção civil (Abreu, 2020). Em paralelo a estes empreendimentos, existem a extração de agregados como areia, seixo extraídos em menor escala, mas que apresentam grande importância devido a sua utilização na construção civil (Ibram, 2014).

O estado do Pará passou a apresentar sérias alterações no aspecto ambiental, fundiário, demográfico e social de sua população devido a instalação desses complexos minerários. A principal consequência dessa mudança ambiental ocorreu nas Florestas Nacionais de domínio públicos e constituídas de espécies nativas que têm como objetivo fundamental o uso múltiplo e sustentável dos recursos florestais (Brasil, 2000).

O Município de Ourém, no Estado do Pará, possui grandes reservas de seixo, e tornou-se um dos principais fornecedores desse minério no estado, devido sua localização próxima a grandes centros urbanos (Souza; Pena; Silva, 2016). Em 2015, foram extraídas 256.274 toneladas (Dnpm, 2016). Essa extração, no entanto, pode acarretar diversos impactos ambientais ao município, principalmente se não for realizada de acordo com a legislação vigente (Pinheiro, 2016).

As operações de lavra de seixo no município de Ourém tem início com o desmatamento, descampamento, escavação, carregamento, transporte e restauração das áreas mineradas. O seixo encontra-se em área coberta pela floresta ombrófila densa que tem que ser suprimida para ter acesso a ele. A mesma trata-se de uma floresta do bioma amazônico que apresenta grande diversidade arbórea com grande volume de madeira, sobretudo aquelas de valor comercial (RADAMBRASIL, 1976, Salomão 
et al. 2012). Antes da operação de desmatamento, a empresa tem que fazer o inventário florestal e avaliar a estrutura florestal para possibilitar o aproveitamento de toda a madeira comercial e, também, subsidiar as ações de recuperação florestal das áreas desmatadas.

Para minimizar esta degradação, a Instrução Normativa no06/2014 da Secretaria de Meio Ambiente e Sustentabilidade do Estado do Pará, apresenta os procedimentos e critérios para o licenciamento ambiental de extração de agregados do solo, com a exigência de documentação prévia a exploração que comprovar as medidas feitas para minimizar os impactos ambientais que podem ser gerados na área, bem como outros documentos que comprovem que tais medidas estejam sendo colocadas em práticas (Semas - Pará, 2017).

A Instrução Normativa nº 06/2014 prever, como uma das mais eficazes medidas de recomposição da área após o término da extração, o plantio de mudas de espécies arbóreas. Para este plantio, no entanto, é recomendado que seja realizado um levantamento florístico nas áreas de florestas circunvizinhas às jazidas exploradas, a fim de ser feito o reconhecimento das principais espécies arbóreas de ocorrências natural neste local e o plantio ser feito com algumas dessas árvores que sejam adaptadas a crescer nas condições encontradas no local (Semas, 2014).

A mineração do seixo pode causar poluição da água, poluição do ar, poluição sonora (devido ao maquinário utilizado), e subsidência do terreno. Como reflexo desses impactos as áreas exploradas ficam degradadas e perdem a capacidade de repor matéria orgânica do solo, nutrientes, biomassa e o banco de sementes (Silva, 2007).

Uma área degradada por mineração apresenta níveis baixos de nutrientes e com características físico-químicas diferenciadas, quando comparadas ao solo original, para a recuperação de um ecossistema degradado depende das práticas de manejo a serem efetuadas no sítio e de espécies de árvores nativas regional, dando início desta forma, ao restabelecimento dos processos ecológicos (Moreira, 2004).

A restauração visa a função e a estrutura de um ambiente degradado, buscando similaridade com as características anteriores à ação do homem ou distúrbio ambientais causadores da degradação, é um dos desafios que as ciências enfrentam na tentativa minimizar os efeitos da degradação (Young Apud Moreira, 2000).

A revegetação é parte essencial no processo de restauração de áreas degradadas, implicando na seleção de espécies adequadas ao plantio para acelerar os processos de recomposição florística da paisagem antropizada. Moreira (2004) afirma que para o desenvolvimento de novas tecnologias e formas de manejo há que se intensificar pesquisas multidisciplinares para o sucesso da restauração florestal. Os estudos das espécies florestais nativas geralmente relacionam-se principalmente às características botânicas e dendrológicas (Faria et al., 1997).

A identificação de espécies-chave, que são aquelas que controlam a estrutura da comunidade devido à sua abundância, distribuição espacial, biomassa, porte ou cobertura e que influenciam a ocorrência das demais espécies associadas, é de fundamental importância para o sucesso da restauração florestal em áreas degradadas, principalmente por mineração a céu aberto (Salomão et al., 2013).Assim como, compreender a dinâmica dos processos da floresta e visualizando as mudanças, detectando as causas e determinando qualitativamente e quantitativamente o conjunto, constitui um grande desafio nos trabalhos de manejo de precisão para estabelecer relações e previsão de consequências que sejam ambientalmente corretas, economicamente viáveis e socialmente aceitas e justas (Nappo, 2002).

Diante desse contexto, objetivamos recomendar o uso de espécies florestais nativas pré-selecionadas com características ecológicas para favorecer a rápida recuperação de uma área ambiental degradada pela retirada de seixo, onde estas árvores devem ser nativas e propiciar múltiplas utilidades, contribuindo assim para o ecossistema.

\section{Metodologia}

Ourém é um município do nordeste paraense, localizado a uma latitude $01^{\circ} 33^{\prime} 07^{\prime \prime}$ sul e a uma longitude $47^{\circ} 06^{\prime} 52^{\prime \prime}$ 
oeste, com uma altitude de 40 metros do nível do mar (Figura 1). Sua população estimada em 2020 é de 17.961 hab. Possui uma área de $561,710 \mathrm{~km}^{2} \mathrm{~km}^{2}$, seu bioma é o amazônico. A economia do mesmo, gira em torno na exploração de seixo, brita e areia (IBGE, 2017).

Figura 1. Mapa de localização do Município de Ourém-PA, no Brasil.



Fonte: Autores.

O clima do município é quente e úmido e a precipitação pluviométrica apresenta no mínimo $45 \mathrm{~mm}$ mensal no período mais seco e a precipitação acumulada anual é de $2.449 \mathrm{~mm}$. A temperatura média anual é $26,9{ }^{\circ} \mathrm{C}$, com uma amplitude térmica de $2,5^{\circ} \mathrm{C}$, de $27,9^{\circ} \mathrm{C}$ em julho a $25,4^{\circ} \mathrm{C}$ em janeiro (Silva et al., 1998). A vegetação original se enquadra na região fitoecológica de floresta equatorial subperenifólia, restando hoje remanescentes da mesma, dominando na paisagem, a vegetação secundária, denominada de capoeira, em diferentes estádios sucessórios, associada aos diferentes sistemas agrícolas (Silva et al., 1998). O principal rio do município é o Guamá, para o qual vertem quase todos os rios menores do município. Este rio serve de limite oeste entre Ourém e o Município de Capitão Poço, enquanto um de seus afluentes, o rio Caxiú, serve de limite noroeste com o município de São Miguel do Guamá, o igarapé Tauari, a sudoeste, limita com o município de Garrafão do Norte. Além do rio Guamá, uma parte do alto curso do Caeté serve de limite com o município de Bragança (Fapespa, 2016). A estrututa do solo do município é formado pelo Latossolo Amarelo textura média Gley Pouco Húmico distrófico, textura argilosa; Podzólico Vermelho-Amarelo, textura argilosa; Latossolo Vermelho-Amarelo distrófico, textura argilosa e textura média; solos Aluviais eutróficos e distrófico; e Hidromórficos indiscriminados (Fapespa, 2016).

Esta pesquisa é de cunho exploratório e descritiva, com abordagem quantitativa, e quanto aos meios a mesma se enquadra em estudo de caso, onde esta técnica seleciona um objeto de pesquisa restritivo, visando aprofundar os aspectos inerentes ao objeto de pesquisa. O procedimento de coleta de dados foi planejado em função dos objetivos geral e específicos da pesquisa, dessa forma foram realizadas coletas de dados em fontes secundárias e fontes primárias. Baseando-se, primeiramente, na pesquisa exploratória de dados secundários, obtidos por meio de consulta bibliográfica e depois a coleta de dados em fontes primárias sendo realizada através de entrevista pessoal individual do tipo não estruturada e observação direta.

No dia 25 de abril de 2017, foi realizada uma visita técnica na mineradora Vieira, a qual possui uma área de 1090.000 
hectares, para reconhecimento da mesma. Para a retirada do seixo é escavado buracos de 5 a 10 metros de profundidade. Nesta ocasião percebeu-se o estado de degradação da área explorada e a necessidade de recuperação da mesma. A propriedade apresenta cerca de $80 \%$ da área utilizada para a mineradora.

Para responder aos nossos objetivos foi realizado um levantamento das espécies florestais que ocorrem na área do projeto de mineração. Sendo selecionada uma área da propriedade que já tinha sido explorada e que depois foi abandonada. Foi utilizada a estrada como trajeto para percorrer uma extensão aproximada de $3 \mathrm{~km}$ para realizar o diagnóstico florestal. A identificação florestal foi realizada através da observação dos indivíduos adultos nos dois lados da estrada. Foi anotado o nome vulgar e depois feita a correta identificação do nome científico e da família botânica por um identificador botânico da região.

\section{Resultados e Discussão}

Segundo Brienza Junior et al (1995) a floresta é um ecossistema em equilíbrio estável, mas com processos dinâmicos que podem se alterar e se adaptar continuamente. Entretanto, há limites para a capacidade de resistir às mudanças ambientais, sendo que a degradação ocorre quando esse limite é excedido.

A vegetação secundária que surge após a retirada da floresta nativa, caracterizada pela fase de pousio, tem importância prática para o ambiente. A biomassa vegetal acumula nutrientes que é posteriormente decomposta por fungos e bactérias. Entretanto, em locais de alta degradação, comumente recorrente da mineração, estes ambientes ficam abandonados após sua exploração, sem a intervenção adequada o solo encontra dificuldades para a recuperação de sua fertilidade (Figura 2).

Figura 2: Vista aérea de uma área abandonada depois da exploração do minério de seixo no município de Ourém.

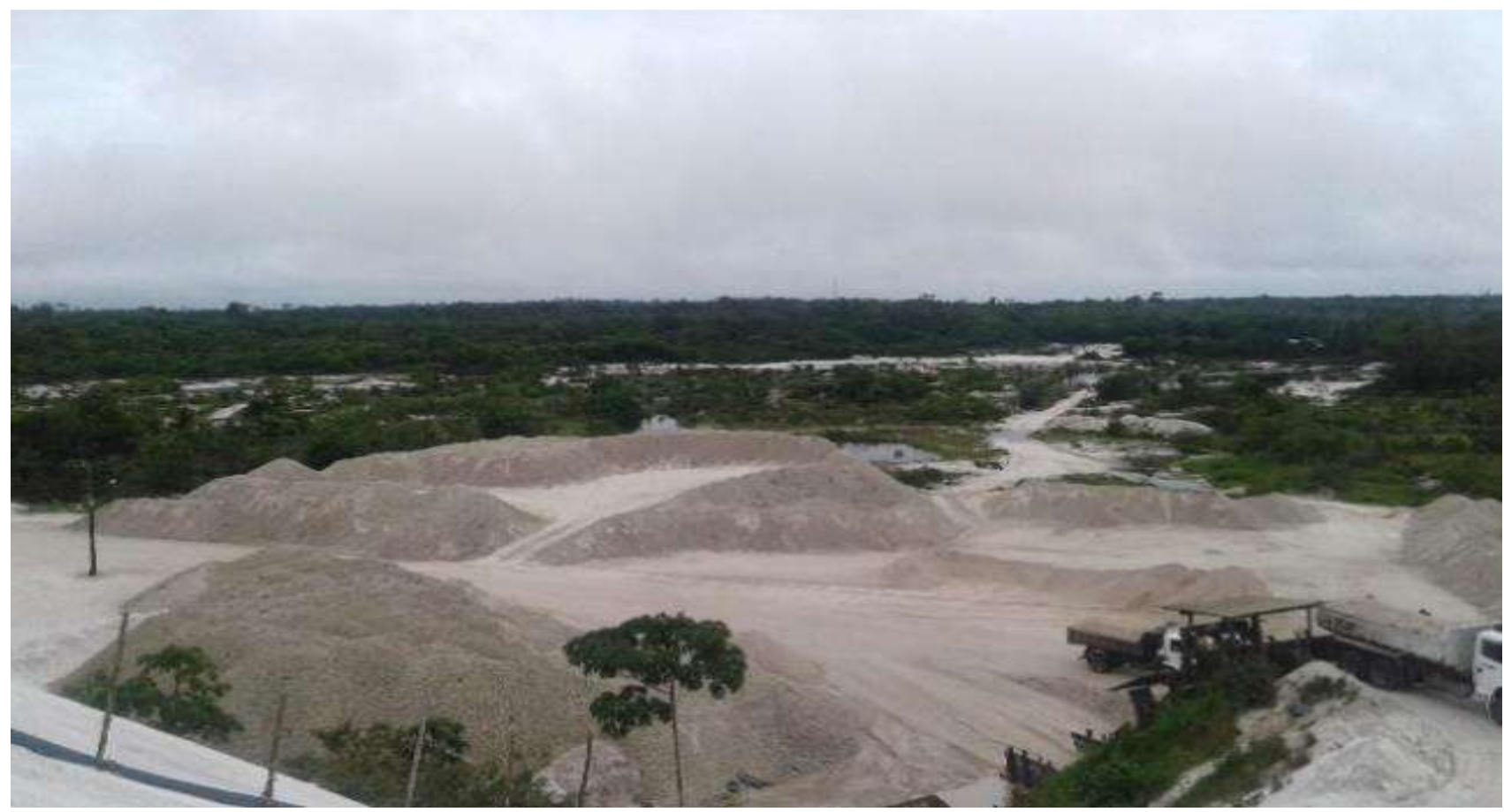

Fonte: Autores.

Na Figura 2, pode ser observadas dunas de areias formadas pela retirada de seixo na área, também pode se observar que na mesma área tem potencial de se regenerar espécies secundárias naturalmente, favorecendo a restauração com a utilização de outras espécies através do reflorestamento.

A área de estudo está inserida no nordeste paraense e apresenta espécies de Floresta Ombrófila Densa da Amazônia, com predominância de dois estratos distintos: um emergente e outro uniforme. As principais espécies que ainda podem ser 
encontradas no estrato emergente são: Dinizia excelsa (angelim vermelho), Bertholletia excelsa (castanheira) e Cedrelinga catanaeformis (cedro-arana). O estrato uniforme é caracterizado por Manilkara paraensis (Huber) Standl. (maparajuba), Protium spp (breus) e Pouteria spp (abius). Essa área tratava-se de área floresta com alto volume de madeira de grande valor comercial, e que foi bastante alterada, mas possui sub-bosque limpo e possui boa regeneração natural (Fapespa, 2016).

A lista de espécies (Tabela 1), localizada na empresa Mineradora Vieira, podem ajudar na recuperação de áreas alteradas pelas atividades de mineração de seixo no município de Ourém - PA e de outras áreas com características semelhantes.

Tabela 1 - Composição florística (famílias, espécies nome vulgar). Grupo ecológico (GE): tolerante (To), intolerante (It) e indefinido (In). Grau de comercialização da madeira (GC): comercial (Co), potencial (Po), não-comercial (Nc) e indefinido (In). Uso: alimento para humanos (AH), alimento para fauna (AF), uso para medicina (UME) e uso para marcenaria (UMA) das espécies encontradas em uma amostra de minério de seixo.

\begin{tabular}{ccccc}
\hline FAMÍLIA /ESPÉCIES/ N. VULGAR & GE & GC & USO
\end{tabular}

Anacardiaceae

Tapiriria guianensis Aubl. (Tatapiririca)

Anacardium spruceanum Benth. ex Engl. (Cajui)

Apocynaceae

Hancornia speciosa Gomes (Mangabeira)

Araliaceae

Schefflera morototoni (Aubl.) Maguire, Steyerm. \& Frodin (Morototó)

Arecaceae

Euterpe oleracea Mart. (Açaí)

Bignoniáceas

Tabebuia impetiginosa Mart. (Ipê-roxo)

Burseraceae

Protium apiculatum Sw. (Breu andirobinha)

\section{Caryocaraceae}

Caryocar villosum (Aubl.) Pres. (Pequiá)

\section{Clusiaceae}

Platonia insignis Mart. (Bacuri)

Symphonia globulifera L. f. (Ananim)

\section{Elaeocarpaceae}

Sloanea nitida G.Don - (Urucurana)

\section{Fabaceae}

Bowdichia spp. (Sucupira)

Cedrelinga catanaeformis (Ducke) Ducke (cedro-arana)

Dinizia excelsa Ducke (Angelin vermelho)

Hymenolobium petraeum Ducke (Angelim Pedra)

Hymenaea courbaril L. (Jatobá)

Hymenaea parvifolia Huber (Jutai)

Inga edulis Mart. (Inga - Cipó)

Parkia nítida Miq. (Faveira)

Piptadenia suaveolens (Mcq)Mimosaceae. (Timborana)
It

It

It Po

It Co

AF, UME, UMA

$\mathrm{AH}, \mathrm{AF}, \mathrm{UME}$,

H, AF, UME, UMA

UME.UMA

AH, AF, UME, UMA

UME, UMA

To Po

It $\quad \mathrm{Co}$

AH, AF, UME, UMA

It $\mathrm{Co}$

$\mathrm{AH}, \mathrm{AF}, \mathrm{UME}$,

It $\mathrm{Co}$

It $\quad \mathrm{Nc}$

AF, UME, UMA

UME, UMA

UMA

UMA

UMA

To $\mathrm{Co}$

AH, AF, UME, UMA

To $\quad \mathrm{Co}$

UMA

$\mathrm{AH}, \mathrm{AF}, \mathrm{UME}$

UME, UMA

UMA 
Sclerolobium paniculatum Vogel (Taxi-branco)

Vouacapoua americana Aubl (Acapu)

\section{Goupiaceae}

Goupia glabra AubI. (Cupiúba)

\section{Humiriaceae}

Sacoglottis amazonica Benth (Uxirana)

Endopleura uchi Cuatrec (Uxi)

\section{Lauraceae}

Nectandra rubra (Mez) C.K. Allen. (Louro-vermelho)

Aniba rosaeodora Ducke (Pau Rosa)

Ocotea ssp (Louro amarelo)

\section{Lecythidaceae}

Bertholletia excelsa Humb. \& Bonpl (castanha do Pará)

Malpighiaceae

Byrsonima crassifólia (L.) Rich (Murici)

Meliaceae

Carapa guianensis Aubl. (Andiroba)

\section{Moraceae}

Bagassa guianensis Aubi. (Tatajuba)

Brosimum parinarioides Ducke (Amapá)

\section{Rubiaceae}

Ficus pumila (Unha-de-gato)

\section{Sapotaceae}

Manilkara paraensis (Huber) Standl.(Maparajuba)

Pouteria heterosepala Pires

Pradosia atroviolacea Ducke (Casca doce)

Syzygiopsis oppositifolia Ducke (Guajará)

\section{Simaroubaceae}

Simarouba amara Aubl. (Marupa)

\section{Urticaceae}

Cecropia spp. (Embaúba)

Vochysiaceae

Qualea albiflora Warm (mandioqueira)

Vochysia maxima Ducke (Quaruba verdadeira)

Vochysia spp. (Quaruba)
It Po

UMA

To

Co

AF, UME, UMA

It $\quad \mathrm{Co}$

AF, UME, UMA

UME, UMA

To $\quad \mathrm{Co}$

$\mathrm{AH}, \mathrm{AF}, \mathrm{UME}$

UME, UMA

UME, UMA

UME, UMA

AH, AF, UME

$\mathrm{AH}, \mathrm{AF}$

It $\quad \mathrm{Nc}$

Co

AF, UME, UMA

UMA

UMA

UME

UMA

To $\quad \mathrm{Co}$

To $\mathrm{Co}$

To $\mathrm{Co}$

AH, AF, UME, UMA

To $\mathrm{Co}$

UMA

UMA

AF, UME, UMA

It $\quad \mathrm{Nc}$

$\mathrm{AH}, \mathrm{AF}$

UMA

UMA

Fonte: Autores.

A presença numerosa de famílias com tolerância a sol e de espécies pioneiras foi registrado na área, demonstrando a diversidade florística desse ambiente e a qualidade do sítio. Foram registradas espécies típicas das florestas tropicais amazônicas com importante valor madeireiro, como Bertholletia excelsa Humb. \& Bonpl (castanha do Pará), Aniba rosaeodora Ducke (Pau Rosa) e Vouacapoua americana Aubl., espécies ameaçadas de extinção no Brasil, demostrando que precisamos conservar e melhorar ecossistemas degradados.

Espécies indicadas para recuperação de áreas degradadas pela extração de seixo no Município de Ourém - PA. 
Após a visita técnica realizada em abril de 2018, no município de Ourém, onde foi observado impactos ambientais causados pelas seixeiras na localidade, com isso realizou-se pesquisas bibliográficas e foi coletado informações através de entrevista com moradores do município, absorvendo dos seus conhecimentos empíricos, o que possibilitou identificar as espécies nativas do local para uma possível recuperação de forma sustentável dessas áreas alteradas.

Para que um processo de sucessão se desenvolva, é necessário que: exista uma área aberta onde espécies vegetais possam se estabelecer e sobreviver, que novas espécies possam chegar ao longo do tempo, ou que sementes pré-existentes no solo germinam introduzindo novas espécies nessa área, e também que as espécies que vão ocupando a área tenham comportamentos ecológicos distintos, promovendo uma gradual substituição de espécies na área, aspecto que caracteriza a sucessão (Rodrigues; Gandolfi, 2004).

Em virtude disto, foi possível indicar espécies nomeadas como adequadas para a recuperação de solos arenosos e degradados, e que possibilite retorno monetário e sustentável para os proprietários, tais como:

Angelim-pedra (Dinizia excelsa Ducke) é emergente e pode atingir até $60 \mathrm{~m}$ de altura e até mais de $2 \mathrm{~m}$ de diâmetro. O tronco é reto e cilíndrico, com base acanalada e sapopemas altas. Ramifica no alto, compondo uma copa frondosa e bem distribuída, com galharia pesada, destacando-se na floresta natural. A espécie é classificada como pioneira, e a madeira pode ser utilizada na construção civil e naval, em construções leves e pesadas, sendo utilizados em uso externo, como dormentes, postes, torneados, moirões, pontes, estacas, andaimes, dormentes, esteios, vigamentos, e no uso interno, como caibros, vigas, ripas, tacos e tábuas para assoalho, molduras, batentes de portas e janelas, marcenaria e carpintaria. Devido ao seu grande porte, a madeira é geralmente usada em peças grandes e inteiras (Embrapa Amazônia Oriental 2004; Ferreira et al. 2004; Ferreira \& Hopkins 2004).

Taxi-branco (Sclerolobium paniculatum Vogel) é uma árvore de porte médio (30 $\mathrm{m}$ de altura) que pode alcançar o dossel superior em florestas secundárias (Lima, 2004). A copa da árvore é arredondada e densa. O tronco é tortuoso e cilíndrico. A casca externa é de cor branco-acinzentado, a interna é arroxeada com seiva da mesma cor. $\mathrm{O}$ alburno é bege claro, pouco diferenciado do cerne irregular (Ipef, 2004).

O Taxi-branco, além de apresentar rápido crescimento e elevada produção de liteira, também possui, a capacidade de fixação de nitrogênio atmosférico. Por isso a espécie é muito utilizada na recuperação de áreas alteradas. O taxi-branco destaca-se pela rusticidade e rápida formação de liteira, que proporcionam condições favoráveis para o estabelecimento de outras espécies pioneiras importantes para promover maior biodiversidade no processo de seleção natural. O taxi-branco pode ser empregado em carpintaria, arborização urbana, para produção de moirões, dormentes e estacas, além de fabricação de embalagens. As flores são apícolas. Não é adequada para produção de papel e celulose, por apresentar alto teor de lignina. É recomendada para ornamentação de parques e arborização de rodovias. A árvore, por suas características de rusticidade e de rápido crescimento, é amplamente recomendada para reflorestamentos heterogêneos destinados à recuperação de áreas alteradas (Carvalho, 1994; Lorenzi, 2002; Carvalho, 2003; IPEF, 2004).

Andiroba (Carapa guianensis Aubl.) no Pará, floresce entre o mês de agosto e outubro e seus frutos amadurecem entre janeiro e abril. Nem todos os anos as árvores de andiroba produzem frutos. (Shanley, 2005). As folhas compostas, alternadas e paripinadas, com um vestígio de um folíolo terminal, tomentoso e glandular. Em média com 30-90 cm de comprimento, podendo chegar até $110 \mathrm{~cm}$. Os frutos são de cápsulas globosa e subglobosa com 4-6 valvas, indeiscente ou deiscente que se separam com o impacto da queda do fruto (Ferraz et.al, 2002).

A semente é utilizada na produção de repelentes, é também utilizada para fins medicinais (chá contra febre, cicatrizantes, tratamento contra bactérias etc.) a madeira é de excelente qualidade, podendo ser usada em construção civil (vigas, caibros, ripas, esquadrias, lambris, venezianas, rodapés, entre outros), fabricação de móveis, lâminas, compensados, caixas de embalagem, mastros e acabamento interno de navios. Em floresta de terra firme, a maioria dos frutos e sementes são 
encontradas embaixo da própria árvore-matriz. No período de dispersão, as sementes de andiroba são consideradas uma fonte de alimento primário e são apreciadas por roedores, tatus, porcos-do-mato, pacas, veados, cotias etc. (Embrapa;2006). É uma árvore de grande e médio porte, com tronco reto, podendo atingir 20-30 metros de altura, de copa densa, com a circunferência (rodo) de 50-120cm (Souza, et al. 2006).

A andiroba é uma árvore de uso múltiplo, podendo ser aproveitada para óleo, casca medicinal e madeira. Que pode gerar lucro para o proprietário da terra. O óleo é um dos produtos medicinais mais vendidos na Amazônia, 1 litro de óleo de andiroba poder ser vendido por $\mathrm{R} \$ 15$ e 1 quilo de casca por $\mathrm{R} \$ 5$ é um produto de interesse internacional sendo exportado para a Europa e Estados Unidos. A semente para plantio de R \$ 7,00 a R \$ 8,00 por Kg (Oliveira; 2013). Já a madeira é vendida nas serrarias do Pará por R \$ 200 o metro cúbico serrado. Para exportação, o metro cúbico não sai por menos de $\mathrm{R} \$ 500$.

Castanha-do-Pará ((Bertholletia excelsa Humb. \& Bonpl.) é uma espécie heliófita encontrada em áreas de floresta de terra firme. Pertence a fase final de sucessão, sendo considerada clímax, e seu tempo de vida é longo (Ávila, 2006). A castanheira pode atingir até 50 metros de altura. As folhas são simples, as flores possuem pétalas branco-amareladas. A castanheira é de uso múltiplo, onde o fruto pode ser utilizado na produção de marshmallow, pães, biscoitos e uma infinidade de outros doces e sobremesas. Na indústria é amplamente utilizado na fabricação de produtos capilares como: shampoo, condicionador, creme, loção, além de perfumes, sabonete, óleos e hidratantes corporais. Também encontramos um mercado crescente na fabricação do azeite da castanha (Souza, et al, 2008).

A madeira é uma das mais valorizadas pela indústria madeireira, sendo indicada para construção civil interna leve, tábuas para assoalhos e paredes, painéis decorativos, forros, fabricação de compensados, embalagens. A espécie é excelente opção para reflorestamentos em áreas degradadas, ao lado de outras espécies florestais. Em floresta nativa sua exploração é proibidadesde 1994 pelo Decreto no 1.282 .

O Cedro (Cedrelinga Catanaeformis) possui como característica o cerne róseo-avermelhado a bege-rosado ou esverdeado; alburno mais claro e lustroso; grã direita a irregular; lisa ao tato; cheiro e gosto imperceptíveis. A madeira de Cedro é de massa específica média, apresentando baixas retratibilidade e resistência mecânica. A madeira de Cedro é de fácil trabalhabilidade, tanto com ferramentas manuais quanto com máquinas. Recebe ótimo acabamento. Encontrada na região Amazônica.

O Bacuri (Platonia insignis Mart.) é uma árvore frutífera e madeireira, no Pará, ele floresce de junho a agosto e os frutos aparecem entre janeiro e abril. Mas a safra desta fruta varia em diferentes regiões do estado, isso prolonga seu fornecimento no mercado, sua madeira, considerada nobre, também tem variadas aplicações. o bacurizeiro aguenta bem o fogo, modo tanto sexuado (por meio de sementes) quanto assexuado (por brotações oriundas de raízes) (Shanley; Medina, 2005).

A sua polpa agridoce rica em potássio, fósforo e cálcio, que é consumida diretamente ou utilizada na produção de doces, sorvetes, sucos, geleias, licores e outras, ou seja, fins alimentícios. A madeira é utilizada na fabricação de móveis, construção civil e naval, também são usados o óleo e o látex amarelo da árvore para fins medicinais.

Árvore mede de 15 a 25 metros de altura e de 1,5 de diâmetro, ou 4 metros de circunferência (rolo), com folhas ocorre naturalmente na capoeira em áreas degradadas e arenosa, as sementes variam de 2-5, dentro da casca. A germinação é de 1 -2 anos, com crescimento rápido ao sol, de 50cm-1 m por ano, a produção demora de 8 a 10 anos. A madeira é muito usada na construção de casas e, atualmente, tem larga aplicação na construção naval artesanal, em virtude da sua adequabilidade para a confecção de determinados componentes de embarcações de pequeno porte, amplamente disseminadas nos rios amazônicos (Carvalho et al. 2002).

O bacurizeiro é uma árvore de usos múltiplos (fruto, madeira, látex), decorrente disto o aumento da procura pela polpa de bacuri elevou seu valor (o preço por quilo passou de $R \$ 10$, em 2005, para $R \$ 40$ atualmente) e indicou que a produção extrativa não tem condições de atender sequer o mercado local. (Homma et.al, 2010) Essa maior pressão de demanda teve 
reflexos nas áreas de ocorrência, induzindo o manejo dos rebrotamentos naturais e o estabelecimento de pomares por agricultores do Pará, já que a fruta também é comercializada externamente (EMBRAPA, 1999).

Cupiúba (Goupia glabra AubI.) A Cupiúba apresenta madeira castanho avermelhada, floresce durante um longo período do ano, especialmente entre outubro e novembro, já seus frutos, amadurecem entre dezembro e janeiro. A floração e de desfolha ocorrem normalmente na estação seca.

A madeira é pesada e dura resistente a mecânica média e boa trabalhabilidade; apresenta moderada resistência a fungos, aos cupins e ao apodrecimento; é usada para diversas finalidades, como vigas, caibros, ripas, batentes de portas e janelas, tábuas para assoalhos e rodapés, dormentes, estacas, mourões, postes, cruzetas, pontes, caixas, engradados, torneados, móveis, embarcações, carrocerias, compensados, faqueados, lenha e carvão. A casca da árvore é popularmente usada como analgésico dentário.

A árvore apresenta 10-40m de altura, com cerne de coloração castanho-amarelada ou bege-clara passando a castanhoavermelhada, textura média a grosseira o tronco retilíneo e cilíndrico pode alcançar até $130 \mathrm{~cm}$ de diâmetro (rolo), ocorre em matas de terra firme em toda a região Amazônica, tanto em terrenos arenosos como argilosos. Essa árvore é indicada para arborização, reflorestamentos homogêneos e heterogêneos, por apresentar rápido crescimento e tolerância à luz direta (Schwengber\& Smiderle, 2005).

O valor econômico e a margem de comercialização da madeira em tora oriunda de áreas manejadas em média dependendo do diâmetro $\mathrm{R} \$ 115,00$ (Santana et. al., 2016).

Ipê roxo (Tabebuia impetiginosa Mart) o ipê-roxo floresce entre maio e setembro e frutifica entre julho e novembro. Após a árvore ficar nua com a queda de suas folhas, cerca de 10 dias ocorre a frutificação. Isso não ocorre todos os anos, existem variações na floração e a não frutificação e às vezes, a árvore deixa de florescer por 1-2 anos seguidos (Revilla; Souza,2005).

A madeira é de alta qualidade, utilizada em construção civil, fabricação de pisos, mourões, embarcações e carvão, da casca interna são feitos chá, xaropes (uso medicinais), das flores são feitos arrojos.

O ipê - roxo, também conhecido como pau d'arco pode chegar até 40 metros de altura e atingir uma circunferência de 4,5 metros. Esta árvore tem ocorrência na terra firme das matas tropicais do Brasil, também ocorre pouco em áreas de várzea e baixo a madeira é muito procurada por isso ela se encontra em pouca abundância na floresta. Já no manejo, o crescimento é de 30 - 75cm por ano (Januario; Silverio-Lopes,2014).

O ipê-roxo é muito explorado pelos madeireiros por causa da boa qualidade da madeira, o valor da madeira até o ano de 2015 era de $R \$ 136,67$ a $R$ \$ 570,00 o m³ , a o valor da casca da árvore para fazer chá (uso medicinal) girava em torno de $R$ \$ 6 por quilo (Filho; Sartorelli ,2015). O tempo de colheita da é madeira entre 40 e 50 anos, mas a retirada da casca já visa lucro para o dono do plantio.

Inga - Cipó (Inga vera Willd) entre os meses de março e maio ocorre a frutificação, crescem rápido, adaptando-se a qualquer tipo de solo. Depois de plantada a muda cresce mais de 2 metros no primeiro ano A árvore é ótima para compor reflorestamentos e para fazer sombra refrescante para as pessoas que tem pressa de terem árvores grandes (Pott \& Pott,2005).

Os frutos são consumidos, sendo muito refrescantes e doces e usada para o sombreamento. A árvore apresenta tronco curto e copa ampla quando cultivada, na floresta crescem de 6 - 18 metros de altura e de largura de 1,64 cm. Ocorrência em solo pode ser profundo, úmido, neutro, com constituição arenosa ou argilosa (solo vermelho) e rico em matéria orgânica (Mata, 2009).

Jatobá (Hymenaea courbaril L.) O jatobá no Pará floresce entre março e maio e frutifica entre agosto e outubro. É uma espécie considerada ameaçada de extinção devido à superexploração. $\mathrm{O}$ fruto é utilizado para fins alimentícios, o fruto pode trazer benefícios à organização mental, o fruto é rico em ferro, e é indicado a quem sofre de anemia; a sua casca é usada fins 
medicinais assim como a sua seiva como a resina; a madeira é utilizada para construção civil nas cidades, no interior é feita para fazer canoas.

É uma árvore de grande porte, com 30-40 metros de altura, possui o tronco reto com cerca de 2 metros de diâmetro (mais de 5 metros de rodo). Ocorre em terra firme, de várzeas, mais frequentes em solos argilosos e pobres. no manejo a árvore tem o crescimento da árvore é de até 0,5 até mais que 1 metro por ano, a produção de semente com 8 -12 anos (Shanley,2005).

Uxi (Endopleura uchi Cuatrec.) O uxi flora entre os meses de outubro e novembro, os frutos caem no mês de fevereiro e maio. Do fruto são feitos picolés, sorvetes, suco, ou seja, para alimentação humana e para animais também, a madeira é extraída para indústria e para marcenaria; sua casca é de uso medicinais; e suas sementes têm uso para artesanato.

É uma arvore de grande porte com cerca de 25 a 30 metros de altura, 1 metro de diâmetro ou 3 metros de rolo, ocorre com frequência em mata alta ou terra firme, ocorre com frequência em estuário. O crescimento é lento na sobra o crescimento com exposição ao sol pode chegar até 1 metro por ano, a produção em plantio, começa com 7 a 10 anos

No Estado do Pará, uma das mais antigas e importantes áreas de ocupação agrícola da Amazônia, possuem grandes extensões de floresta secundária (capoeira) que apresentam a participação de cerca de $25 \%$ das espécies nativas da floresta original. Por outro lado, inúmeras espécies perdem a capacidade de se estabelecerem nas capoeiras, como por exemplo Manilkara paraensis (maparajuba), Carapa guianensis (andiroba) e Theobroma grandiflorum (cupuaçu), todas de grande valor econômico regional (Vieira et al. 1995).

Acapu (Vouacpoua americana Aubl.) tem crescimento lento, potencial valor econômico e ocorre em subpopulações reduzidas nos Estados do Amapá, Pará, Amazonas e Maranhão. Sua madeira é muito utilizada na construção civil e naval. Apesar da legalização da extração, considerando dados de porte, estima-se a supressão de 37.826 indivíduos de grande porte ou 282.747 ind. de porte mediano, no período de 2006 a 2011. Além disso, a espécie ocorre em áreas que sofrem forte antropização, onde o declínio da qualidade do hábitat é constante. Estima-se que o tempo de geração seja de 90 anos, no mínimo. Portanto, é possível suspeitar que tenha havido uma redução populacional de pelo menos 50\% nos últimos 90 anos. Recomendam-se estudos populacionais e genéticos e maior fiscalização da retirada da espécie na natureza (CNCFlora, 2012).

Árvore atinge até 40 metros de altura (Oliveira Filho, 2010). Espécie de crescimento lento que não tolera ambientes abertos (Varty \& Guadagnin, 1998). O acapu apresentou declínio contínuo por sobre explotação da madeira (Varty; Guadagnin, 1998). Dados de exploração de madeira nativa no Estado do Pará são alarmantes. A exploração legalizada da espécie, considerando os dados do porte da espécie estimou-se a supressão de 37.826 indivíduos de grande porte ou 282.747 ind. porte mediano, no período 2006 a 2011 (Sema-Pa, 2011).

A região amazônica tem sofrido com os impactos decorrentes do processo crescente de ocupação da região e o esgotamento dos estoques madeireiros, como já se observa a falta de madeira para produção de energia, devido ao intenso uso pelas olarias que atuam na região. É necessário aumentar a oferta de madeira nas proximidades dos centros consumidores, ocupar as áreas degradadas ou abandonadas e adequar-se à exigência da reposição florestal obrigatória. A forma mais eficiente de cumprir essas atividades é o plantio de espécies florestais, tanto em forma de monocultivo como em consórcios. Entretanto, esta atividade esbarra em um empecilho, que é a falta de recomendação sobre quais espécies devem ser plantadas em determinadas áreas.

\section{Conclusão}

Foi observado que os projetos de restauração de áreas degradadas baseiam-se no desencadeamento ou na aceleração do processo de sucessão ecológica, que é o processo através do qual uma comunidade evolui no tempo, tendendo a se tornar progressivamente mais complexa, diversificada e estável.

Embora não tenha ocorrido grande diferença visual na recuperação das áreas através da regeneração natural ocasionou 
o aumento do número de espécies de capoeira. Apesar da alta intervenção ocorrida nessas áreas de mineração, a floresta ao entorno demonstra que com o estudo de chuva de sementes, o reflorestamento de espécies florestais nativos e tratamentos silviculturais aliado a capacidade de se regenerar, pode proporcionar o fechamento do dossel em médio a longo prazo. Para realizar futuras observações para determinar a tendência à estabilidade.

Entretanto, vale ressaltar que foram encontradas dificuldades para a realização desta pesquisa, pois há ausência de divulgação e/ou disponibilidade de materiais e documentos relacionados a problemática das áreas degradadas por seixeiras no local estudado.

Serão feitos tratamentos silviculturais no banco de plântulas dessa área para conduzir as espécies florestais em consórcio com frutíferas para proporcionar a volta da fauna silvestre.

\section{Referências}

Abreu, G. (2020). Pará é o estado brasileiro que mais exporta produtos minerais. Secom- Secretaria de Comunicação do Estado do Pará. Atualizado em10/07/2020. https://agenciapara.com.br/noticia/20707/.

Ávila, F. (2006). Árvores da Amazônia. Empresa das Artes. 245 p.

Brienza Júnior, S., Vieira, I. C. G, \& Yared, J. A. G. (1995). Considerações sobre recuperação de áreas alteradas por atividades agropecuária e florestal na Amazônia brasileira. Belém: EMBRAPA-CPATU, Documentos, 83. 27p.

Carvalho, J. E. U. De, Müller, C. H., \& Nascimento, W. M. O. (1999). Métodos de Propagação do Bacurizeiro (Platonia insignis Mart.). Embrapa-CPATU, Comunicado Técnico, 11. 5p.

CNCFlora. (2012). Vouacapoua americana in Lista Vermelha da flora brasileira versão 2012.2 Centro Nacional de Conservação da Flora. http://cncflora.jbrj.gov.br/portal/pt-br/profile/Vouacapoua americana.

Embrapa Amazônia Oriental. 2004. Espécies arbóreas da Amazônia no. 6: Angelim-vermelho, Dinizia excelsa. Embrapa Amazônia Oriental, Belém, PA. 6p.

Fapespa. (2016). Estatística Municipal: Ourém. Governo Do Estado Do Pará, Diretoria De Estatística E De Tecnologia E Gestão Da Informação. http://www.parasustentavel.pa.gov.br/wp-content/uploads/2017/04/Ourém.pdf.

Faria, J. M. R., Davide, A. C.\& Botelho, S. A. (1997). Comportamento de espécies florestais em área degradada, com duas adubações de plantio. Cerne, Lavras, 3, 25-77.

Ferraz, I. D. K., Filho, N. L., Imakawa, A. M., Varela, V. P. \& Piñarodrigues, F. C. M. (2004). Características básicas para um agrupamento ecológico preliminar de espécies madeireiras da floresta de terra firme da Amazônia Central. Acta Amazonica. 34(4): 621-633.

Ferreira, G. C. \& Hopkins, M. J. G. 2004. Manual de identificação botânica e anatômica - Angelim. Embrapa Amazônia Oriental. 101p.

Ferreira, G. C., Hopkins, M. J. G., \& Secco. R. S. (2004 ${ }^{a}$ ). Contribuição ao conhecimento morfológico das espécies de leguminosae comercializadas no estado do Pará, como "angelim". Acta Amazonica. 34(2) 219-232.

IBGE- Instituto Brasileiro de Geografia e Estatística. (2017)| Brasil Pará Ourém. v4.6.2. https://cidades.ibge.gov.br/brasil/pa/ourem/panorama.

Maini, L.S. (1992). SustainabIe development of forests. Unasylva. 169, 3-8.

Mesquita, M. R., Ferraz, I. D. K., \& Camargo, J. L. C. Angelim-vermelho. Dinizia excelsa Ducke. Fabaceae. (2009). Manual de sementes da Amazônia. Fascículo 8. 2009. 11 p. https://www.inpa.gov.br/sementes/manuais/fasciculo8_Dinizia_excelsa_WEB.pdf.

Moreira, P. R. (2004). Manejo do solo e recomposição da vegetação com vistas a recuperação de áreas degradadas pela extração de bauxita, Poços de Caldas, MG.155 f. Tese (Doutorado em Ciências Biológicas) - Universidade Estadual Paulista, Rio Claro.

Nappo, M. E. (2002). Dinâmica da regeneração natural de espécies arbóreas e arbustivas no sub-bosque de povoamentos de Mimosa scabrella Bentham, em área minerada, em Poços de Caldas-MG. 2002. 86 f. Tese (Doutorado em Ciências Florestais) - Universidade Federal de Viçosa.

Oliveira-Filho, A. T. (2012). TreeAtlan 2.0, Flora arbórea da América do Sul cisandina tropical e subtropical: Um banco de dados envolvendo biogeografia, diversidade e conservação. Universidade Federal de Minas Gerais. http://www.icb.ufmg.br/treeatlan.

Pinheiro, C. S. S. Extração de areia e seixo desenvolvimento ou degradação? O caso de Porto Grande/AP. Dissertação (MESTRADO). Universidade Federal do Pará. Belém - Pará. 134 p. 2016.

RADAMBRASIL. (1976). Folha SA.21 - Santarém. Rio Janeiro: Ministério das Minas e Energia, Departamento Nacional da Produção Mineral. 10. 310414.

Rodrigues, R. R. \& Gandolfi, S. (2004). Conceitos, tendências e ações para a recuperação de Florestas Ciliares. In Rodrigues, R.R. \& Leitão Filho, H.F. Matas Ciliares: Conservação e Recuperação. EDUSP/FAPESP 235-247. 
Research, Society and Development, v. 10, n. 9, e32310916937, 2021

(CC BY 4.0) | ISSN 2525-3409 | DOI: http://dx.doi.org/10.33448/rsd-v10i9.16937

Salomão, R. Paiva, Santana, A. C., \& Brienza Júnior, S. (2013). Seleção de espécies da floresta ombrófila densa e indicação da densidade de plantio na restauração florestal de áreas degradadas na Amazônia. Ciência Florestal, 23, 139-151.

Salomão, R. P., Brienza Júnior, S. \& Santana, A. C. (2012). Análise da florística e estrutura de floresta primária visando a seleção de espécies-chave, através de análise multivariada, para a restauração de áreas mineradas em unidades de conservação. Revista Árvore, 36,. 989-1008. https://doi.org/10.1590/S010067622012000600001

Santana, A. C., Santana, Á. L., Oliveira, C. M. \& Costa, N. L. (2016). O Valor Econômico da Extração de Madeira em Tora na Ilha do Marajó, Pará. 22, Brazilian Journal of Theoretical and Applied Economics, Universidade de Passo Fundo. DOI: https://doi.org/10.5335/rtee.v22i47.6812.

SEMA-PA. Extração e Movimento de Toras de Madeira Nativa. Período de 1/1/2006 até 23/10/2011.

Silva, L. G. T., Silva, B. N. R. Da, Rocha, A. M. A. Da, \& Sarmanho, S. M. N. (1998). Interação de fatores biofísicos e do uso da terra na dinâmica da paisagem do município de Ourém, Pará, em sistema de informação geográfica. Belém: Embrapa-CPATU. Documentos, 133. 33p.

Souza, C. R. De, Azevedo, C. P. De., Rossi, L. M. B., \& Lima, R. M. B. De. (2008). Castanha-do-brasil (Bertholletia excelsa Hurnb. \& Bonpt).). Manaus: Embrapa Amazônia Ocidental. Documentos, 60. 22 p.

Souza, C. R. De, Lima, R. M. B. De, Azevedo, C. P. De, \& Rossi, L. M. B. (2006). Andiroba (Carapa guianensis Aubl.). - Manaus: Embrapa Amazônia Ocidental. Documentos, $48,21 \mathrm{p}$.

Souza, C. R. De, Lima, R. M. B. De, Azevedo, C. P. De, \& Rossi, L. M. B. (2004). Taxi-branco (Sclerolobium paniculatum Vogel)-Manaus: Embrapa Amazônia Ocidental, Documentos, 34, 23 p.

Swaine, M. D. \& Withmore, T. C. (1988). On the definition of ecological species groups in tropical rain forests. Vegetation, 75: 81-86.

Varty, N., \& Guadagnin, D. L. (2011). Vouacapoua americana in IUCN Red List of Threatened Species. 2, IUCN. IUCN. www.iucnredlist.org. 